\title{
Successful treatment of uncomplicated gonococcal urethritis in HIV-infected patients with single-dose oral cefpodoxime
}

\author{
George Psevdos Jr MD, Victoria Sharp MD
}

G Psevdos Jr, V Sharp. Successful treatment of uncomplicated gonococcal urethritis in HIV-infected patients with single-dose oral cefpodoxime. Can J Infect Dis Med Microbiol 2010;21(3):e109-e110.

Fluoroquinolones are no longer recommended for the treatment of gonococcal infections in the United States. Cephalosporins - ceftriaxone and cefixime - are the treatment of choice, as suggested by the Centers for Disease Control and Prevention (USA). There are limited data on the efficacy of cefpodoxime for the treatment of uncomplicated gonococcal infections. Two cases of HIV-infected homosexual men who were successfully treated with cefpodoxime for urethritis caused by Neisseria gonorrhoeae are described in the present study.

Key Words: Cefpodoxime; HIV/AIDS; Neisseria gonorrhoeae

Cluoroquinolone-resistant Neisseria gonorrhoeae is widely 7 dispersed in the United States (US). The US Centers for Disease Control and Prevention (CDC) no longer recommends fluoroquinolones for the treatment of gonococcal urethritis (1). The CDC recommends cephalosporins - ceftriaxone and cefixime - for the treatment of uncomplicated gonococcal infections of the urethra, cervix and rectum (1). Ceftriaxone is given intramuscularly; cefixine, an oral agent, was not easily available in the US for a significant period of time. Other single-dose cephalosporins are suggested as alternatives, with oral cefpodoxime being the likely choice. In a small study (2), a single $400 \mathrm{mg}$ oral dose of cefpodoxime showed $100 \%$ efficacy. A few US health departments (California, Washington and North Carolina) have approved the $400 \mathrm{mg}$ oral dose of cepfodoxime to be an acceptable alternative treatment $(3,4)$. We report two cases of HIVinfected homosexual men who presented with uncomplicated gonococcal urethritis, and were successfully treated with a single $400 \mathrm{mg}$ oral dose of cefpodoxime.

Case 1

\section{CASE PRESENTATIONS}

A 34-year-old Hispanic homosexual man presented with penile discharge. The patient was HIV positive and was receiving antiretroviral treatment with lopinavir-ritonavir, lamivudine and abacavir; his $\mathrm{CD}^{+}$cell count was $489 / \mu \mathrm{L}$ and his HIV viral load was less than 50 copies/mL. The patient denied any sexual activities. On physical examination, a Prince Albert ring was noted; the ring entered through the penile meatus into the urethra and exited through a hole pierced on the top of the
Le traitement réussi d'une urétrite gonococcique sans complication chez des patients infectés par le VIH, au moyen d'une monodose de cefpodoxime par voie orale

Les fluoroquinolones ne sont plus recommandées dans le traitement des infections gonococciques aux États-Unis. Les céphalosporines, soit la ceftriaxone et la céfixime, sont le traitement de première intention, conformément à la suggestion des Centers for Disease Control and Prevention des États-Unis. On possède peu de données sur l'efficacité du cefpodoxime pour le traitement des infections gonococciques sans complication. Dans la présente étude, les auteurs présentent le cas de deux hommes homosexuels infectés par le VIH qui ont pris avec succès de la cefpodoxime pour traiter une urétrite à Neisseria gonorrhoeae.

glans penis. Purulent discharge was noted in the urethra and adjacent to the ring. Gram stain showed rare neutrophils and rare Gram-positive cocci. The patient's urinalysis showed 50 to 100 white blood cells per high-power field. Urethral culture revealed Streptococcus agalactiae, however, no $N$ gonorrhoeae. The DNA probe (Gen-Probe Inc, USA) was positive for gonorrhea, and negative for Chlamydia trachomatis. The patient received an empirical course of ciprofloxacin for seven days and was re-evaluated at the end of the treatment period. He reported no further discharge; however, only a strange tingling at the meatus. He removed the ring and cleaned it with alcohol. This time, the urethral culture revealed $N$ gonorrhoeae; the DNA probe was also positive for gonorrhea. The patient received a one-time dose of $400 \mathrm{mg}$ cefpodoxime. He was reevaluated seven days later, and repeat urethral culture and DNA probe were both negative for gonorrhea. The patient's symptoms resolved immediately after receiving cefpodoxime, and the medication was well tolerated.

Case 2

A 26-year-old African American man presented with dysuria and seepage from the penile meatus. He was diagnosed with HIV infection seven months previously and had not started antiretroviral treatment because his $\mathrm{CD}^{+}$cell count was $778 / \mu \mathrm{L}$ and his HIV viral load was 17,668 copies/mL. He was treated for syphilis three months previously with doxycycline, even though he was not allergic to penicillin; he declined any intramuscular treatment. The patient disclosed multiple unprotected sexual encounters with other men. He adamantly refused to undergo a urethral culture test and declined intramuscular treatment with

Columbia University College of Physicians and Surgeons, Center for Comprehensive Care, St Luke's Roosevelt Hospital, New York, New York, USA

Correspondence: Dr George Psevdos Jr, 1000 10th Avenue, Suite 2T, Samuels Clinic, St Luke's Roosevelt Hospital, New York, New York 10019,

USA. Telephone 212-523-6500, fax 212-523-7182,e-mail gpsevdos@chpnet.org 
ceftriaxone. Purulent discharge was noted at the meatus. The patient's urinalysis showed detectable leukocyte esterase levels, with 50 to 100 white blood cells per high-power field. A urine transcription-mediated amplification assay (ARUP Laboratories, USA) was positive for both $\mathrm{C}$ trachomatis and $N$ gonorrhoeae. He was treated with $400 \mathrm{mg}$ of cefpodoxime and $1000 \mathrm{mg}$ of azithromycin and was evaluated one week later. He tolerated the medications well and did not present with any more symptoms. The urine transcription-mediated amplification assay was repeated and was negative for both organisms.

\section{DISCUSSION}

$N$ gonorrhoeae is currently inherently resistant to penicillin, tetracycline, sulphonamides and fluoroquinolones (5). The options for treatment are limited.

Ceftriaxone, cefpodoxime and cefixime are third-generation cephalosporins with similar antibiotic spectra including Grampositive and Gram-negative organisms (6). Ceftriaxone costs less than the oral cephalosporins (6). It is not clear whether HIV itself has an effect on the evolution of gonococcal infections and their treatment outcomes, but it is well known that gonorrhea can facilitate HIV transmission.

A study (7) performed by the Sexually Transmitted Diseases Control Branch of the California Department of Public Health (USA) evaluated patients treated with cefpodoxime at its clinics from 2004 to 2007 (7). Among men and women infected at any urogenital or rectal site, $96.5 \%$ (305 of 316 subjects) were cured overall (lower bound of exact 95\% CI [LB 95\% CI] was 93.9\%) (7). Among 281 men with urethral gonorrhea, 96.1\% ( 270 of 281 men) were cured overall (LB 95\% CI was 93.1\%) (7). The current CDC standards classify antimicrobials with a

\section{REFERENCES}

1. Centers for Disease Control and Prevention. Update to CDC's sexually transmitted diseases treatment guidelines 2006: Fluoroquinolones no longer recommended for treatment of gonococcal infections. MMWR 2007;56:332-6.

2. Novak E, Paxton LM, Tubbs HJ, Turner LF, Keck CW, Yatsu J. Orally administered cefpodoxime proxetil for treatment of uncomplicated gonococcal urethritis in males: A dose-response study. Antimicrob Agents Chemother 1992;36:1764-5.

3. California Department of Public Health's Sexually Transmitted Diseases (STD) Control Branch and the California STD Controllers Association. Guidelines for the treatment of chlamydia and gonorrhea cases and exposed sexual partners. <www.std.ca.gov> (Accessed on March 8, 2010).

4. North Carolina HIV/STD Prevention and Care Branch. $<$ www.epi.state.nc.us/epi/hiv/pdf/Cefpodoxime\%20Background $\% 20$ 8-5-2005.pdf> (Accessed on March 8, 2010). gonorrhea treatment efficacy of 95\% and greater and LB 95\% CI of $95 \%$ and greater as recommended agents, and those with efficacies of $95 \%$ and greater and LB 95\% CI of 90\% and greater as alternative agents (8). In the study period, 11 failures were noted. The authors concluded that cefpodoxime could be considered an alternative agent for treatment of uncomplicated urogenital and rectal gonorrhea, especially in settings in which intramuscular therapy is unavailable, impractical or not preferred by the patient. In their cohort, 29\% were men who had sex with men (7). These data, which were presented in an abstract form and were unpublished, did not include HIV coinfection rates.

Treatment failures with oral cephalosporins - cefixime and ceftibuten - although rare, have been reported (9). Given the 11 failures with cefpodoxime reported above, it may be prudent to consider test of cure in selected patients, especially if symptoms persist. When a follow-up clinic visit is unlikely, ceftriaxone should be considered.

\section{CONCLUSION}

Gonococcal infections remain an important public health problem. Effective antimicrobial treatments are currently limited to cephalosporins. A one-time dose of $400 \mathrm{mg}$ oral cefpodoxime can be an alternative treatment with potential benefits of convenience - oral route and, perhaps, more readily available than cefixime - and reduced risk of needlestick injuries to health care workers. More prospective studies are needed to fully assess its efficacy in different population groups, including HIV-infected patients. Ongoing surveillance of antibiotic sensitivities of $N$ gonorrheae is of paramount importance to prevent the spread of resistant organisms and coordinate disease control and prevention.

5. Workowski KA, Berman SM, Douglas JM. Emerging antimicrobial resistance in Neisseria Gonorrhoeae. Urgent need to strengthen prevention strategies. Ann Intern Med 2008;148:606-13.

6. Bartlett JG. The Johns Hopkins ABX Guide: Diagnosis \& treatment of infectious diseases, 2nd edn. Baltimore: Jones \& Bartlett Publishers Inc, 2010.

7. Hall C, McElroy M, Samuel M, et al. Single dose cefpodoxime axetil effective treatment of uncomplicated urogenital and rectal gonorrhea. The 17th International Society for STD Research. Seattle, July 29 to August 1, 2007.

8. Moran JS, Levine WC. Drugs of choice for the treatment of uncomplicated gonococcal infections. Clin Infect Dis 1995;20(Suppl 1):S47-65.

9. Tapsal JW. Neisseria gonorrhoeae and emerging resistance to extended spectrum cephalosporins. Curr Opin Infect Dis 2009:22:87-91. 


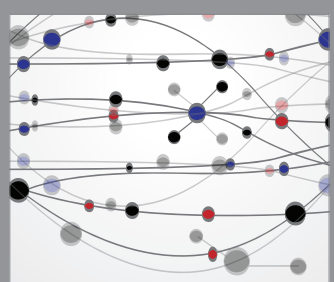

The Scientific World Journal
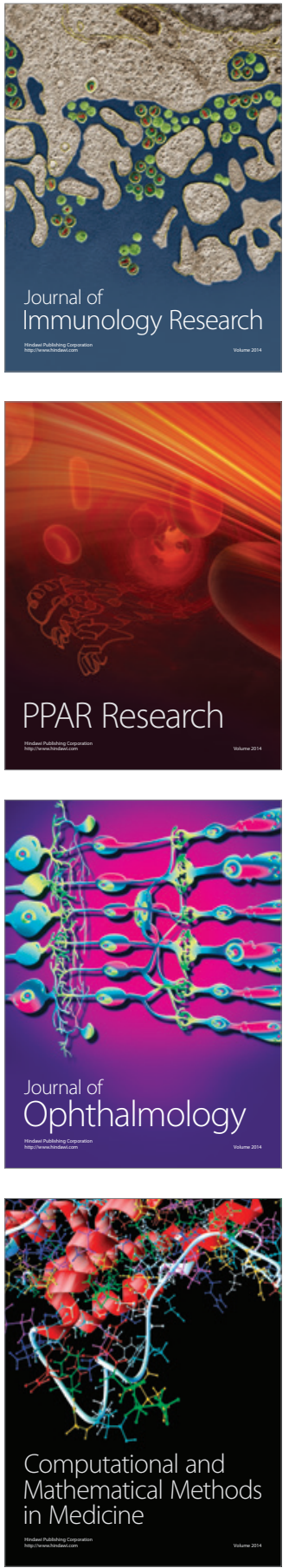

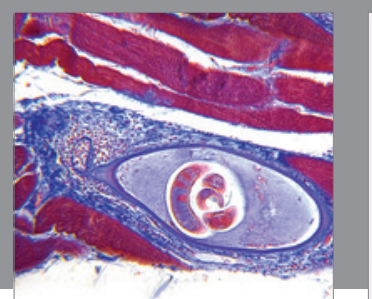

Gastroenterology Research and Practice

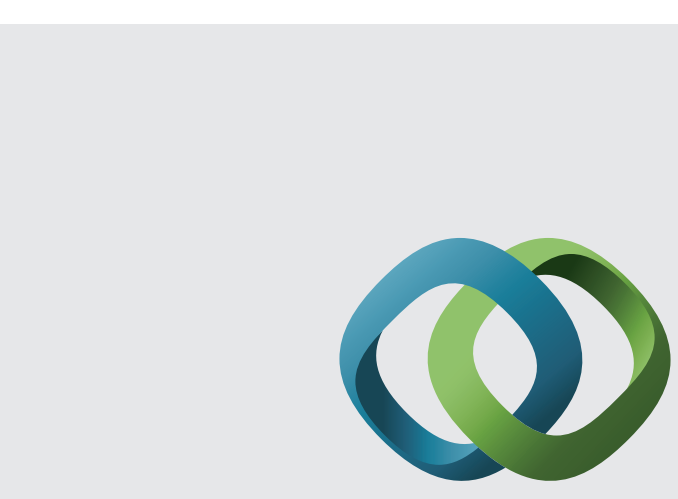

\section{Hindawi}

Submit your manuscripts at

http://www.hindawi.com
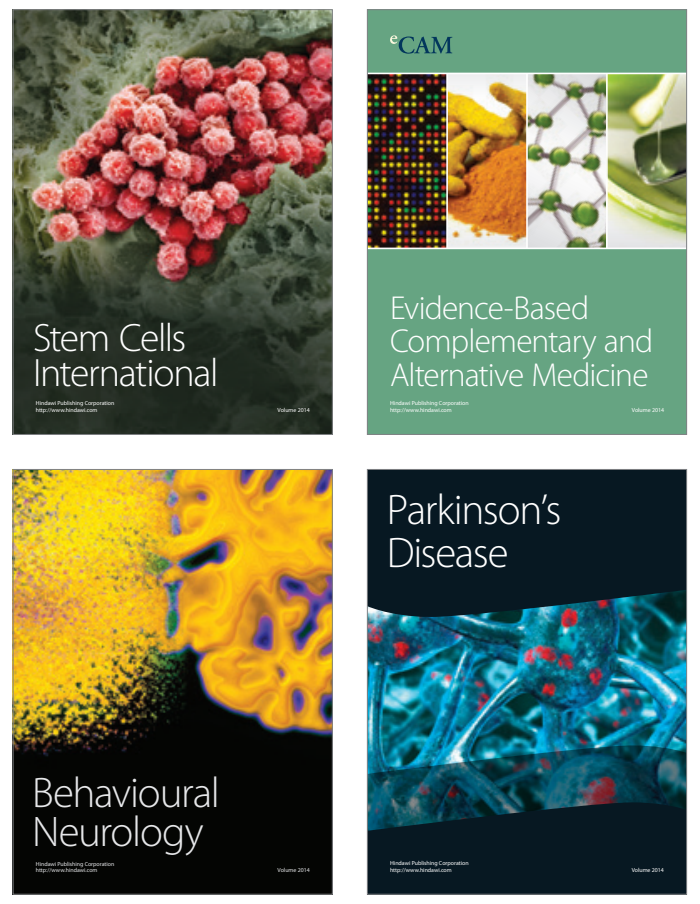
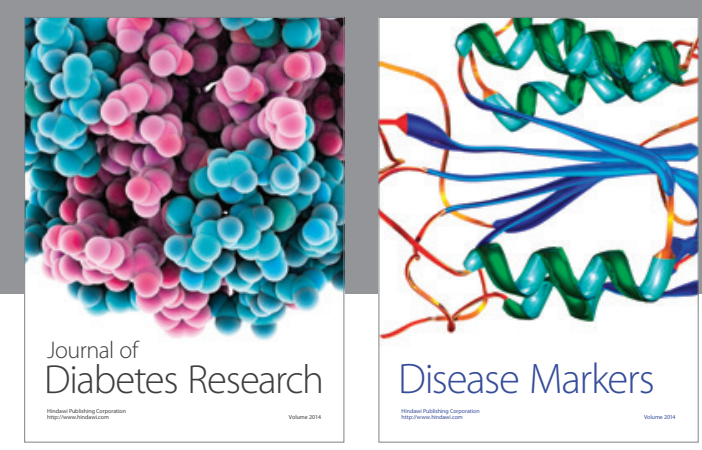

Disease Markers
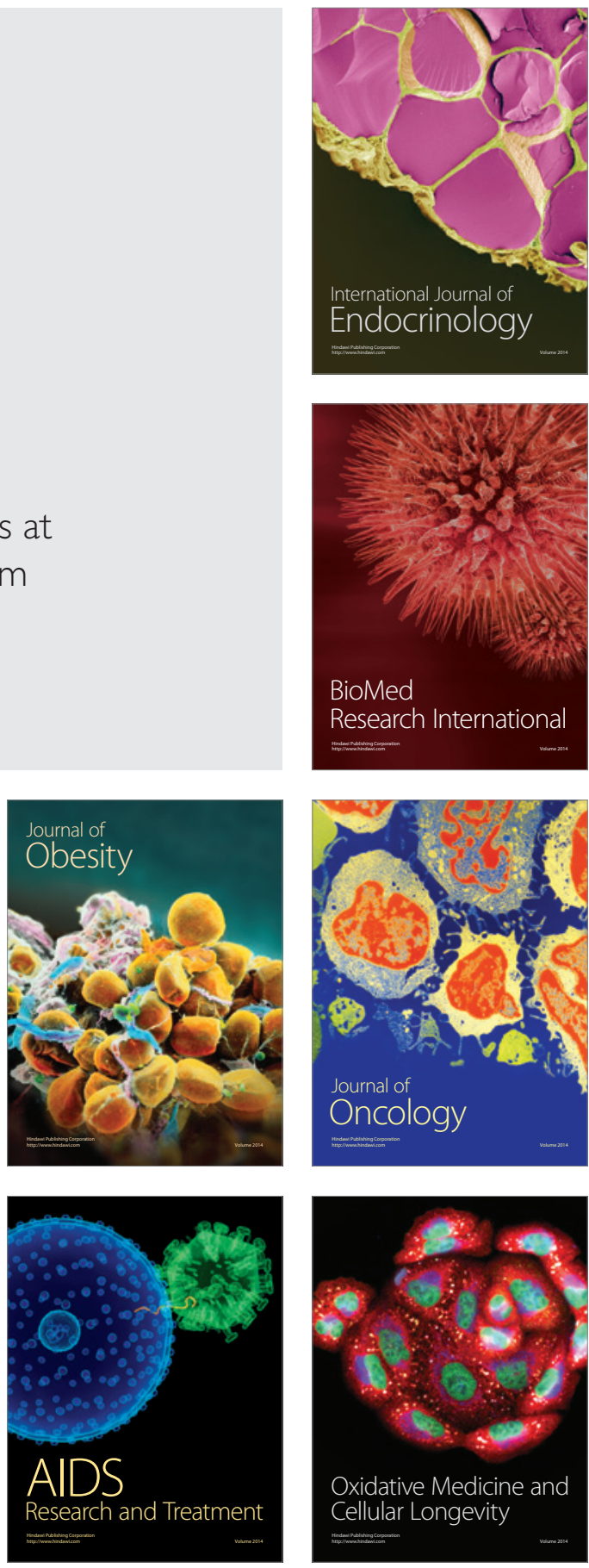